\title{
Influences of groove-type casing treatment on the tip leakage flow behaviour in linear compressor cascades at different tip clearances: influence of single groove at mid-chord
}

\author{
Masanao Kaneko ${ }^{1}$ \\ ${ }^{1}$ Schoool of Science and Engineering, Tokyo Denki University, Saitama, Japan
}

\begin{abstract}
In this study, the influences of the single groove installed at the mid-chord - which is known to have a large expansion effect on the stable operating flow range of low-speed axial compressors - on the flow behaviour and the loss generation in a linear compressor cascade were investigated numerically at different tip clearances. Reynolds-averaged Navier-Stokes simulations of the incompressible flow in the test cascade were performed, with the computed results clarifying the following remarkable phenomena, which are common to both small and large tip-clearance cases. The single groove locally weakens the tip leakage flow by the decrease in the blade loading and the streaming of the flow near the blade pressure side into the groove, consequently reducing the distance between the tip leakage vortex and the blade suction surface. Meanwhile, although the groove decreases the loss due to the tip leakage vortex generated from the blade leading edge, the loss generation in the entire cascade passage is almost the same as that in the cascade without the groove due to the additional loss generation resulting from the presence of the groove.
\end{abstract}

Section: RESEARCH PAPER

Keywords: Gas turbine; compressor; tip leakage flow; casing treatment; circumferential groove

Citation: Masanao Kaneko, Influences of groove-type casing treatment on the tip leakage flow behaviour in linear compressor cascades at different tip clearances: influence of single groove at mid-chord, Acta IMEKO, vol. 10, no. 1, article 37, March 2021, identifier: IMEKO-ACTA-10 (2021)-01-37

Editor: Momoko Kojima, NMIJ, Japan

Received May 15, 2020; In final form July 30, 2020; Published March 2021

Copyright: This is an open-access article distributed under the terms of the Creative Commons Attribution 3.0 License, which permits unrestricted use, distribution, and reproduction in any medium, provided the original author and source are credited.

Corresponding author: Masanao Kaneko, e-mail: kaneko@mail.dendai.ac.jp

\section{INTRODUCTION}

Demand for the improvements in aviation and industrial gas turbine performances in terms of, for example, efficiency has been exponentially increasing due to the worsening global environmental problems and the concern for the depletion of fossil fuels. In light of these social demands, various studies related to an axial-compressor-constituting gas turbine have been carried out to specifically increase the efficiency and the pressure ratio per single stage and to extend the stable operating flow range.

In the aforementioned type of gas turbine, an open impeller is generally used as the rotor impeller. Here, clearances are inevitably present between the rotating blade tips and the stationary shroud casing wall. As a consequence, flow is generated through the tip clearance due to the pressure difference between the blade pressure and the suction surfaces, which subsequently affects the loss generation significantly through the generation of the tip leakage vortex [1]-[4].
Moreover, the interface between the tip leakage flow and the main flow is shifted toward the upstream as the flow rate decreases. When this interface reaches the cascade inlet, the blockage due to the tip leakage flow influences the inception of the rotating stall, which is regarded as one of the factors that restricts the operating flow range [4], [5].

A circumferential groove casing treatment (CGCT) is one of the techniques used to improve a compressor's aerodynamic performance. The CGCT controls the tip leakage flow behaviour through the single or multi groove installed on the shroud casing wall and this consequently shifts the minimum stable flow rate toward a lower flow rate. The influences of the groove location and the number of grooves on the expansion effect related to the stable operating range have been investigated by numerous researchers [6]-[14]. However, while it has been reported that the CGCT reduces the efficiency at certain operating points [6], this mechanism has not been comprehensively investigated. 
Meanwhile, the axial-compressor-constituting gas turbine is generally composed of several pairs of rotors and stators, which are referred to as 'stages'. In this type of compressor, the blade height is gradually reduced toward the final stage. As a result, in the rear stage, since the tip clearance size for the rotor blade height increases in relation to that in the front stage, the influence of the tip leakage flow on the aerodynamic performance is increased [7], [15]-[18]. Therefore, to intensify the improvement effect of the CGCT on the aerodynamic performance of the rear compressor stage, clarifying the influence of the tip clearance size on the flow phenomena generated by the CGCT is also crucial.

The aim of this study was to ascertain how to maximise the expansion effect of the CGCT on the stable operating flow range of the rear compressor stage without a trade-off such as the efficiency penalty. As part of a preliminary study, the influences of the single groove installed at the mid-chord - which is known to have a large expansion effect on the stable operating flow range of low-speed axial compressors [8] - on the flow behaviour and the loss generation in a linear compressor cascade were investigated at different tip clearances. In the following 2 and 3 sections, the test cascade and the computational method and condition used in this study will be explained, respectively. The influences of groove at small and large tip clearance cases will be discussed in the 4 section and the conclusions derived from this study will be summarised in the final section.

\section{TEST CASCADE}

Figure 1 shows the configuration of the test compressor cascade, with its specifications provided in Figure 2 and Table 1. This test cascade is a linear compressor cascade that incorporates two-dimensional blades characterised by the blade tip shape of the GE Rotor B Section Blade and by varied tip clearances. An experimental investigation of the tip leakage flow behaviour in

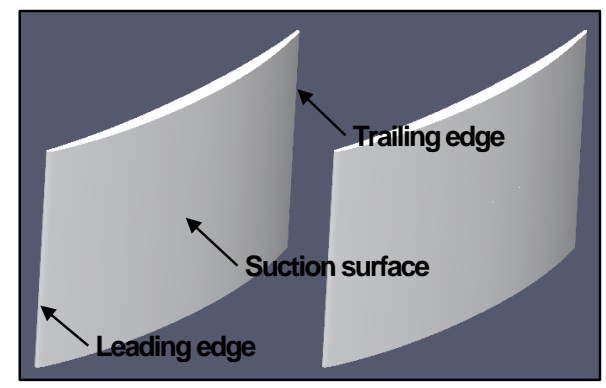

Figure 1. The test cascade.

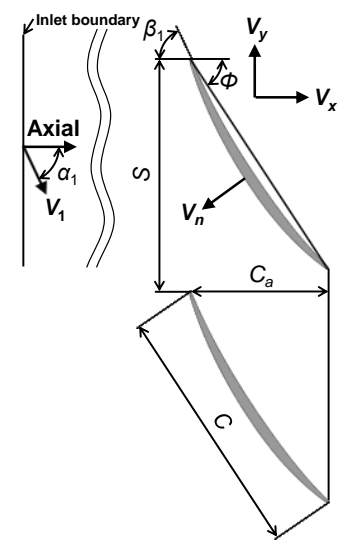

Figure 2. Configuration of the test cascade.
Table 1. Test cascade specifications.

\begin{tabular}{ll} 
Chord $C$ & $254 \mathrm{~mm}$ \\
Axial chord $C_{a}$ & $139 \mathrm{~mm}$ \\
Pitch $S$ & $236 \mathrm{~mm}$ \\
Span $H_{b}$ & $249.8 \mathrm{~mm}$ \\
Inlet blade angle (Measured from axial direction) 81 & $65.1 \mathrm{deg}$. \\
Stagger angle (Measured from axial direction) $\Phi$ & $56.9 \mathrm{deg}$. \\
Solidity $C / S$ & 1.08 \\
\hline
\end{tabular}

this cascade was conducted under subsonic flow conditions at Georgia Institute of Technology [19]. In the present study, the flows in the two types of cascade were analysed numerically at different tip clearances. The first cascade has a smooth wall as the tip side endwall (SW), while the other has an endwall in which a single groove is installed (GW). The tip clearance sizes were set to $4.2 \mathrm{~mm}(1.65 \%$ of $C)$ and $1.27 \mathrm{~mm}(0.5 \%$ of $C)$. The groove shape is shown in Figure 3 and was designed with reference to [8].

\section{NUMERICAL ANALYSIS}

\subsection{Computational method}

In this study, the computations were performed using the open source computational fluid dynamics (CFD) code OpenFOAM. The flow in the cascade was assumed to be a steady-state incompressible flow and the Reynolds-averaged Navier-Stokes (RANS) equation was used as the governing equation in order to clarify the time-averaged effect of the groove on the flow in the compressor. Meanwhile, the SIMPLE algorithm was adopted as the solution algorithm, while the convection term was estimated using the MUSCL scheme while considering both the convergence of the computation and the accuracy of the computed results. The low-Reynolds-type SST $k-\omega$ model [20], which is well known to accurately predict the flow in turbomachinery [12], was chosen as the turbulence model.

\subsection{Computational condition}

In order to reduce the computational resources, the computational domain was set to the tip side endwall from the midspan in the single passage. The inlet and outlet boundary planes were arranged at $1 C$ upstream of the cascade inlet and $2 C$ downstream of the exit, respectively, while the computational grids were generated using the $H$ - and $C$-type structured grids. The total number of cells of the SW was approximately 5.5 million, while that of the GW was approximately 6.8 million. The computational grid used in this study is shown in Figure 4.

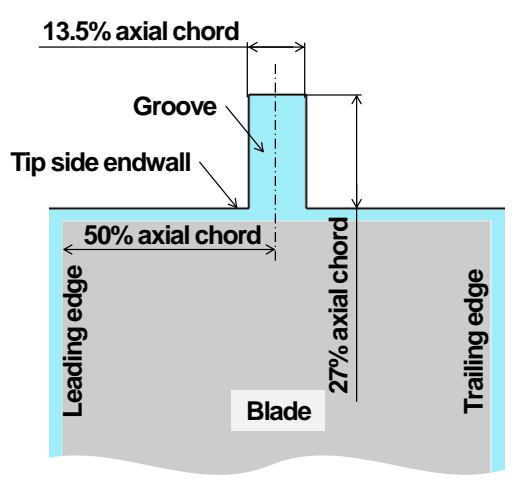

Figure 3. The groove shape. 


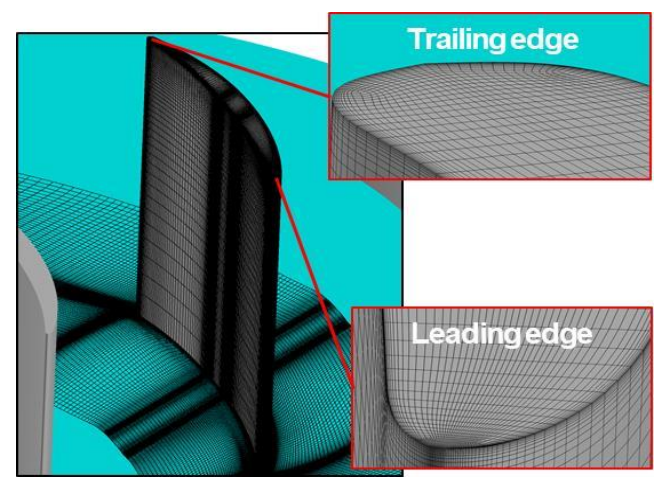

Figure 4. The computational grid.

In terms of boundary conditions, the inlet velocity $V_{1}$ and the inlet flow angle $a_{1}$ were applied uniformly at the inlet boundary. With reference to the experimental conditions described in [19], the $V_{1}$ and the $a_{1}$ measured from the axial direction were set to $25.5 \mathrm{~m} / \mathrm{s}$ and $65.1 \mathrm{deg}$., respectively. Meanwhile, the free-stream boundary was used at the outlet boundary, while the cyclic boundary condition was applied at the pitchwise boundary plane. In order to reveal the basic flow phenomena generated by the single groove, the motion of the tip side endwall relative to the blade row was not considered in this study.

\subsection{The $Y^{+}$distribution and the validation of the computed results}

Figure 5 shows the dimensionless wall distance $Y^{+}$distribution on the blade surface and the SW, while Figure 6 shows the axialwise distribution of the static pressure coefficient $C_{p s}$ on the blade surface at midspan. In the latter figure, the $X / C_{a}$ is the axialwise length normalised by the blade axial chord length and takes 0 at the leading edge (LE) and 1.0 at the trailing edge (TE). The $C_{p s}$ can be defined by the following equation:

$$
C_{p s}=\frac{P_{s}-P_{s 1}}{P_{t 1}-P_{s 1}}
$$

where $P_{s}$ is the static pressure, and $P_{s 1}$ and $P_{t 1}$ are the crosssectional mass averaged values of the static and the total pressures at $X / C_{a}=-1.3$, respectively.

In order to accurately predict the flow field using the lowReynolds-type turbulence model, it is recommended that the

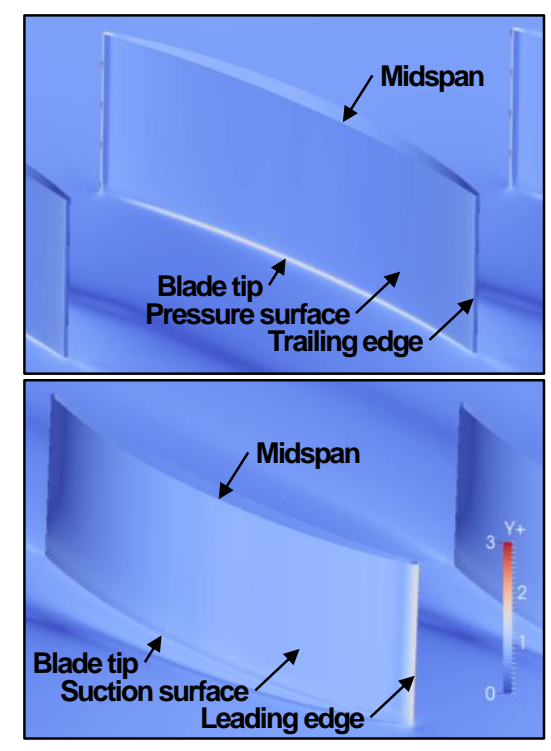

Figure 5. The $\gamma^{+}$distribution on the wall surface.

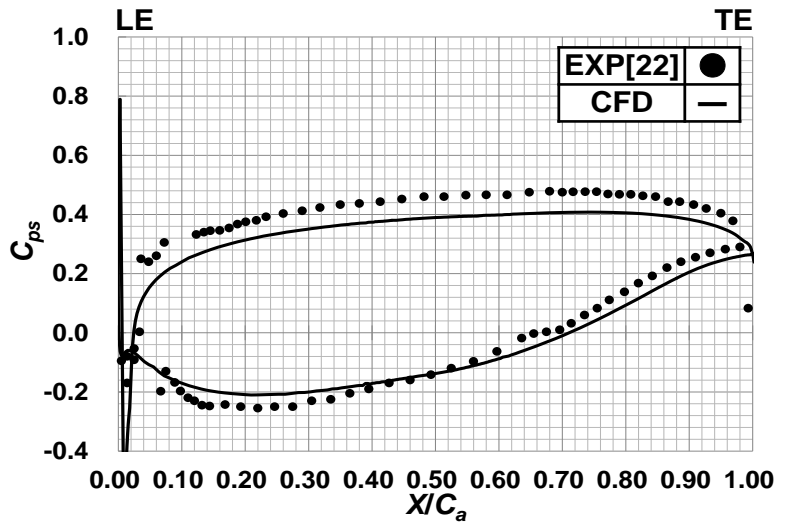

Figure 6. Blade surface static pressure distribution at midspan.

dimensionless wall distances $Y^{+}$on the wall surfaces are set to less than 1 . In terms of my computed results, the $Y^{+}$became less than 1 on almost all of the wall surfaces, as shown in Figure 5. Meanwhile, following a comparison between the computed results and the experimental data, the quantitative differences were found to be small, as shown in Figure 6. However, the computed results well captured the qualitative tendency observed in the experimental data. Therefore, it can be stated that the computed results accurately predicted the flow behaviour in the test cascade.

\section{RESULTS AND DISCUSSION}

In this section, the investigation into the influences of the single groove on the flow behaviour and the loss generation in the cascade is described in terms of both the small and the large tip-clearance cases.

Figure 7 shows the axialwise distribution of the static pressure coefficient $C_{p s}$ on the blade surface near the blade tip, while Figure 8 presents the streamlines with the origin near the midgap at the blade suction side in the tip clearance. In the latter figure, the streamline colours are varied depending on the location of the origins (upstream of groove: red; groove location: black; downstream of groove: blue), while $S S$ and PS indicate the blade suction and pressure surfaces, respectively. Meanwhile, Figure 9 shows the trajectory of the tip leakage vortex core generated from the blade leading edge, while Figure 10 indicates the axialwise and pitchwise momentums $\psi_{x}{ }^{*}$ and $\psi_{y}{ }^{*}$ of the tip leakage flow through the surface $S_{\text {tc }}$, which is the blade suction surface extended from the blade tip to the tip side endwall. The $\psi_{x}{ }^{*}$ and $\psi_{y}{ }^{*}$ are defined by the following equations and indicate the non-dimensional axialwise and the pitchwise momentums per unit length at each axial location, respectively [23]:

$$
\begin{aligned}
& \Psi_{x}^{*}=\int_{\text {Blade tip }}^{\text {Endwall }} \Psi_{x} d z / S_{1} \\
& \Psi_{y}{ }^{*}=\int_{\text {Blade tip }}^{\text {Endwall }} \Psi_{y} d z / S_{1}
\end{aligned}
$$

where $\psi_{x}$ is $\varrho V_{n} V_{x} / \varrho V_{1} V_{1}$ and $\psi_{y}$ is $\varrho V_{n} V_{y} / \varrho V_{1} V_{1}$. As shown in Figure $2, V_{n}$ is the velocity component normal to the $\mathrm{S}_{\mathrm{tc}}$, and $V_{x}$ and $V_{y}$ are the axialwise and pitchwise velocity components, respectively, while $\varrho$ is the density and $S_{1}$ is the cross-sectional area at the cascade inlet. Figure 11 shows the flow rate $Q_{g}$ of the tip leakage flow through surface $S_{g}$, which was normalised by the 
flow rate through the single passage, while Figure 12 presents the spanwise velocity $V_{z}$, which was normalised by the $V_{1}$, distribution on the interface between the groove and the bladeto-blade passage. Meanwhile, Figure 13 indicates the total pressure loss coefficient $C_{p t}$ distribution on the planes normal to the blade chord line and the streamlines with the origin around the high loss regions (LR). The $C_{p t}$ can be defined by the following equation:

$$
C_{p t}=\frac{P_{t 1}-P_{t}}{P_{t 1}}
$$

where $P_{t}$ is the total pressure.

Table 2 presents the mixed-out averaged total pressure loss coefficient $C_{p 22, m}$ downstream of the cascade. The $C_{p r 2, m}$ can be defined as follows:

$$
C_{p t 2, m}=\frac{P_{t 1}-P_{t 2, m}}{P_{t 1}},
$$

where $P_{t 2, m}$ is the mixed-out averaged total pressure at $X / C_{a}=1.3$. The mixed-out value was obtained according to the procedure proposed by Prassad [23].

\subsection{Small tip clearance}

In this section, I discuss the influences of the groove on the flow behaviour and loss generation in the cascade with a small tip clearance.

In the SW, the flow through the tip clearance due to the pressure difference between the blade pressure and the suction surfaces generated the leakage vortex from the blade leading edge (TLV), as shown in Figure 7 and Figure 8a. This vortex was also generated in the GW, as shown in Figure 8b. However, around the groove location, the distance between the TLV core and the blade suction surface was reduced compared to that in the SW, as shown in Figure 9. The distance between the TLV core and the blade suction surface depends not only on the momentum of the main flow but also on that of the tip leakage flow. Thus, the influence of the groove on the momentum of the tip leakage flow was investigated.

Here, the negative $\psi_{x}{ }^{*}$ and $\psi_{y}{ }^{*}$ around the groove location were increased compared to those in the SW, as shown in Figure 10, and this phenomenon was deemed to reduce the distance between the TLV core and the blade suction surface. The increase in $\psi_{x}{ }^{*}$ and $\psi_{y}{ }^{*}$ were believed to be due to the fact that the blade loading near the blade tip decreased around the groove

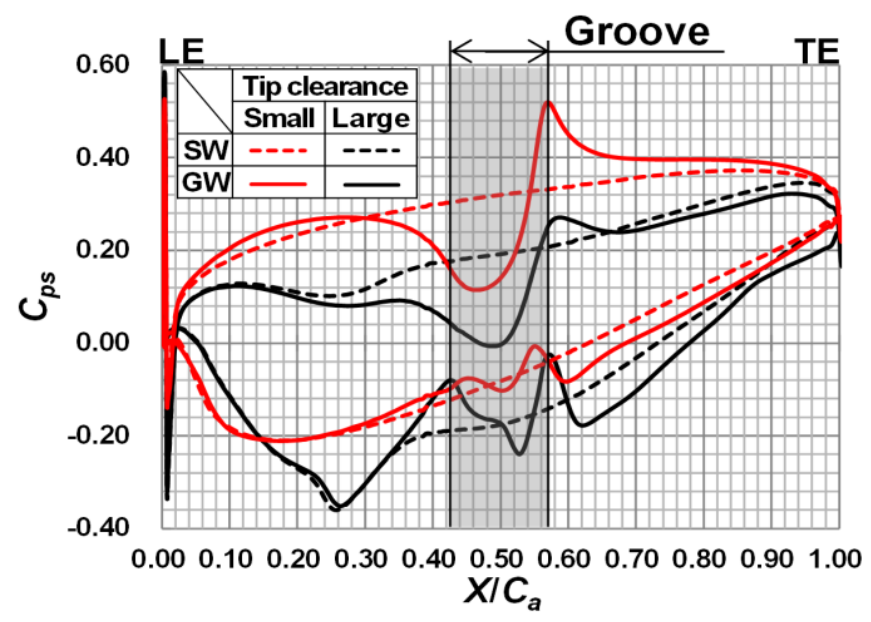

Figure 7. Blade surface static pressure distribution near the blade tip.

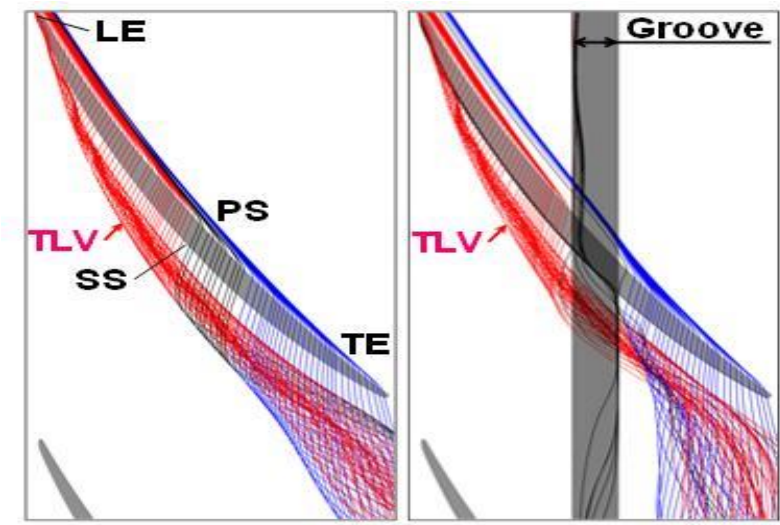

(a) SW (small tip clearance)

(b) GW (small tip clearance)

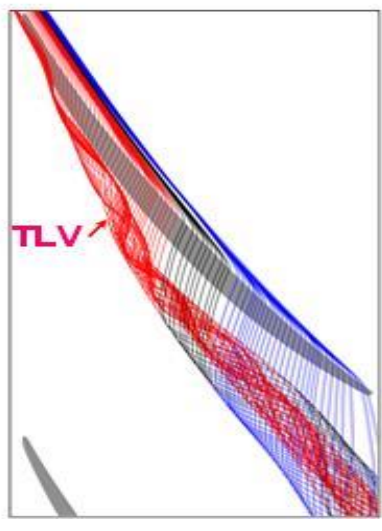

(c) SW (large tip clearance)

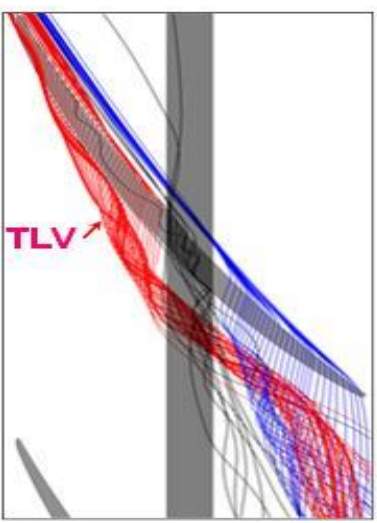

(d) GW (large tip clearance)

Figure 8. Behaviour of tip leakage flow.

location, which consequently reduced the $Q_{g}$ compared to that in the SW, as shown in Figure 7 and Figure 11. Moreover, as Figure 12a shows, the flow around the blade pressure side flowed into the groove, and this phenomenon then further decreased the $Q_{g}$. The influence of the groove on the TLV behaviour can be summarised as follows. First, the groove weakened the flow indicated by the black streamlines in the SW (Figure 8a) via the decrease in the blade loading around the groove location and the flowing of the flow near the blade pressure side into the groove then it inclined its flow direction toward the main flow direction.

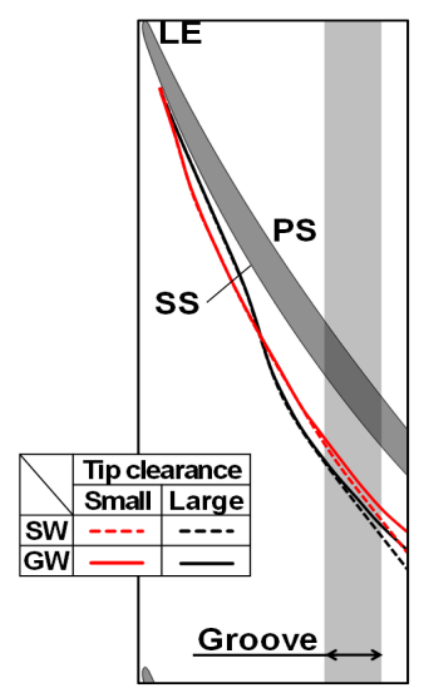

Figure 9. Trajectory of TLV core. 

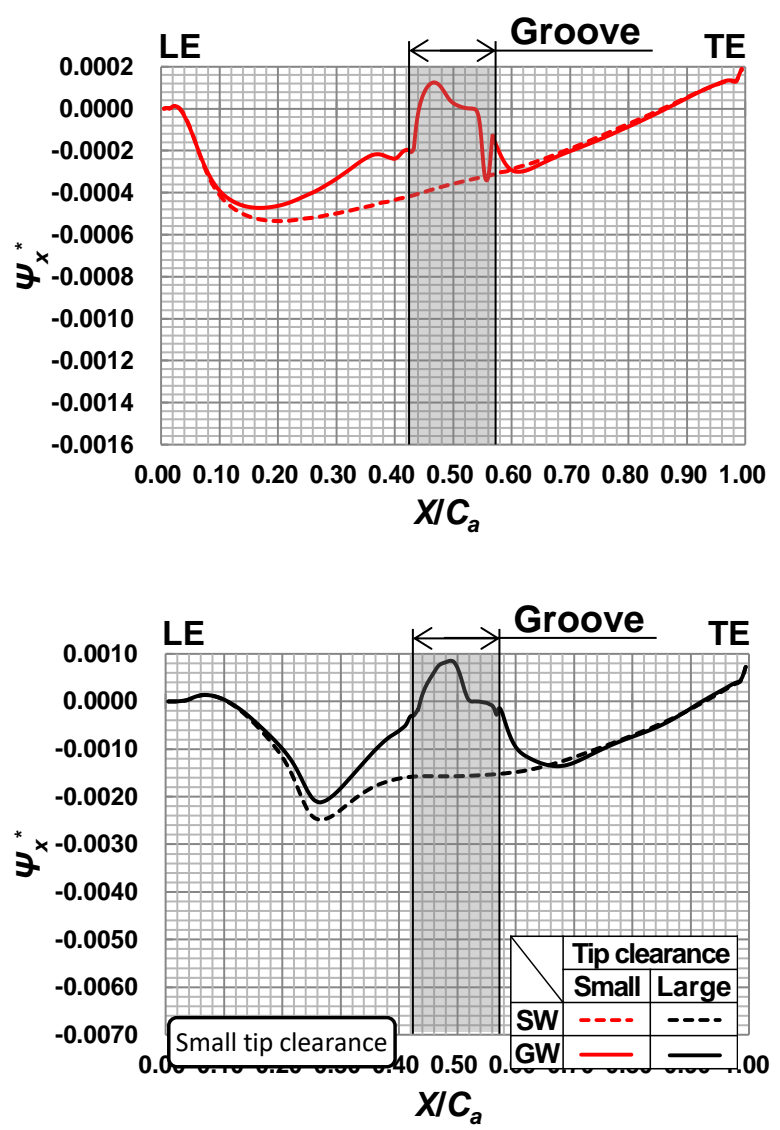

(a) Axialwise
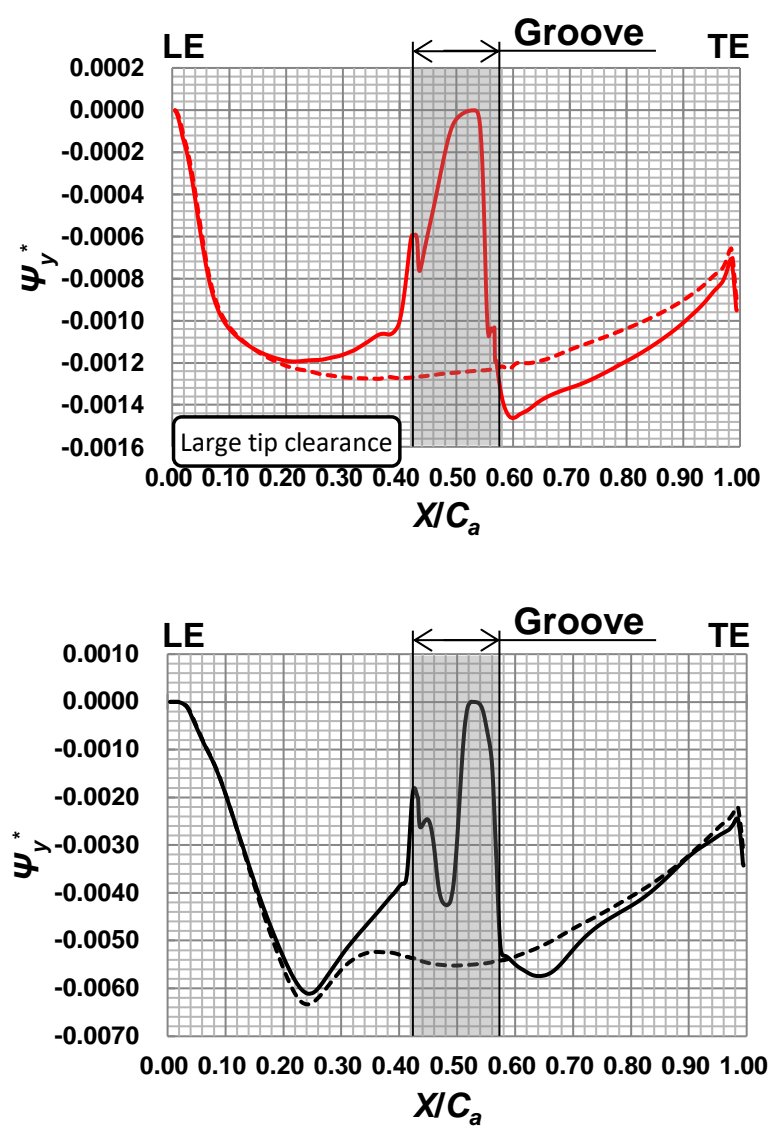

(b) Pitchwise

Figure 10. Momentum components of tip leakage flow.
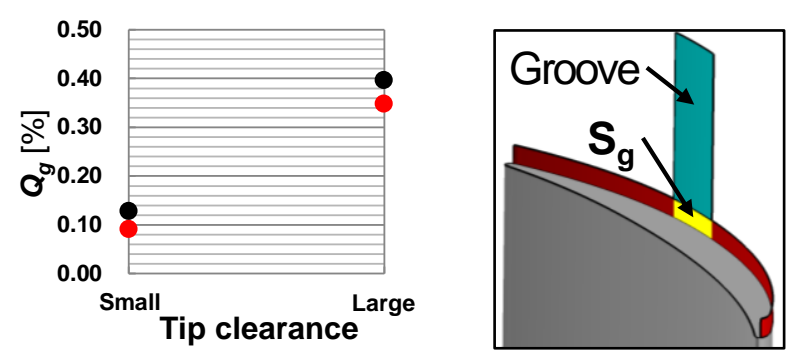

Figure 11. Flow rate through $\mathrm{S}_{\mathrm{g}}$.

As a result, the distance between the TLV core and the blade suction surface was reduced.

Next, the influence of the single groove on the loss generation was investigated. In the SW, the high loss region was distributed around the trajectory of the TLV core, as shown in Figure 13a,

with a similar phenomenon also observed in the GW. However, downstream from the groove location, the high loss region due to the TLV was slightly reduced compared to that in the SW, as is clear from a comparison between Figure 13a and Figure 13b. Here, as Figure 13b show $\mathbf{S W}$ eparation bubble generated on the blade tip surface flow $\mathbf{G W}$ ig the downstream sidewall of the groove (black streamlines) and consequently generated the high loss region LR2. Moreover, the blade loading near the blade tip suddenly increased downstream the groove, as shown in Figure 7. This phenomenon produced the additional tip leakage vortex and consequently generated the high loss region LR3 (purple streamlines in Figure 13b). While the loss generation due to the TLV was reduced in the GW, the $C_{p t 2, m}$ value was almost the same as that in the SW, as shown in Table 2. This was believed to be due to the generation of the LR2 and the LR3.

\subsection{Large tip clearance}

The influence of the groove on the flow behaviour and the loss generation at the large tip clearance was investigated in terms of comparing it with the influence at the small tip clearance.

In the SW, the TLV was also observed in the large tip clearance case, as shown in Figure 8c. However, toward the downstream of the cascade, the distance between the TLV core and the blade suction surface was further increased compared to that in the small tip clearance case, as shown in Figure 9.

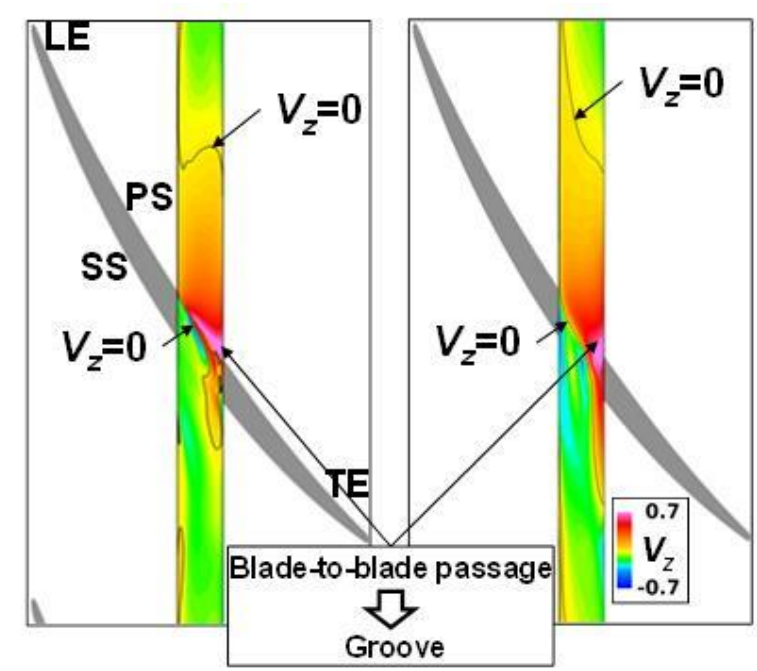

$\begin{array}{ll}\text { (a) GW (small tip clearance) } & \text { (b) GW (large tip clearance) }\end{array}$

Figure 12. Spanwise velocity distribution on interface between groove and blade-to-blade passage. 


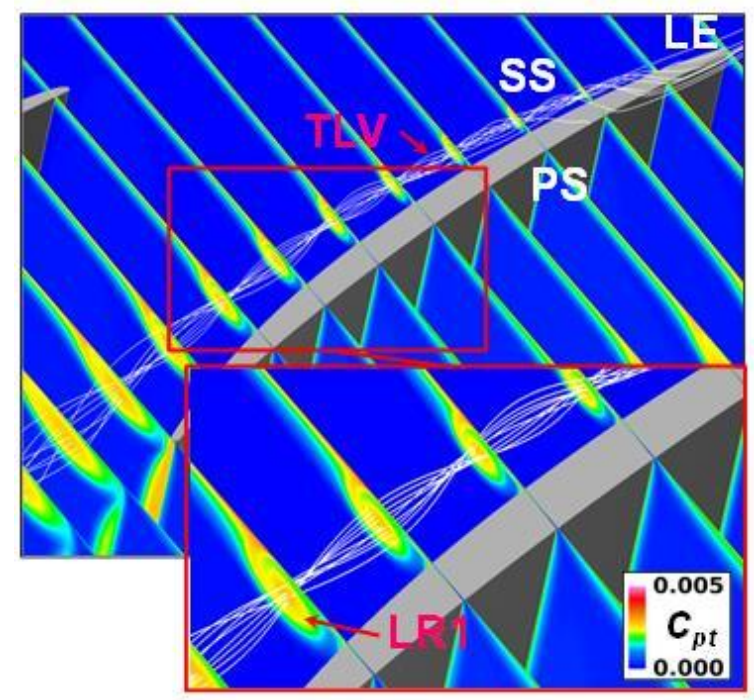

(a) SW (small tip clearance)

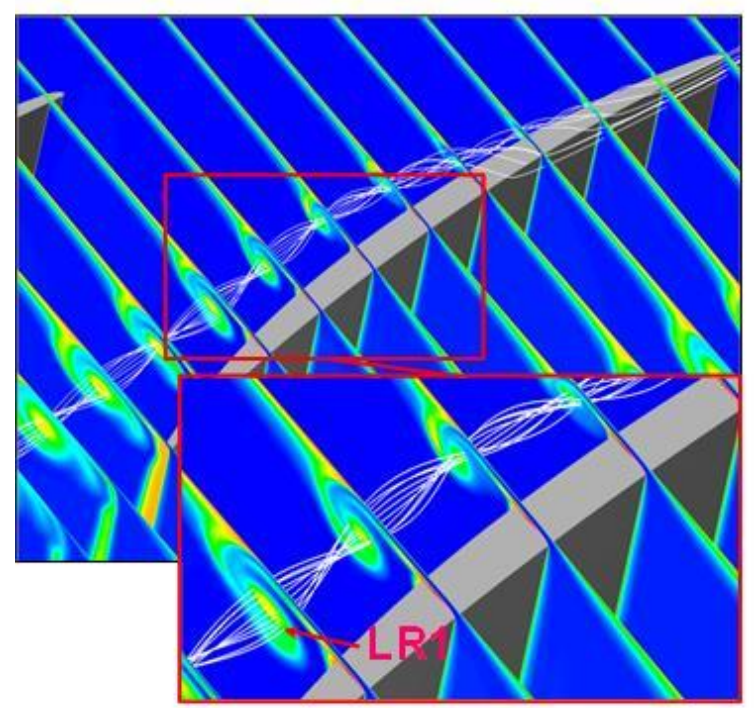

(c) SW (large tip clearance)

Figure 13. Total pressure loss coefficient distribution.

In the large tip clearance case, the TLV was also generated in the GW, as shown in Figure 8d. Around the groove location, the single groove reduced the distance between the TLV core and the blade suction surface compared to that in the SW, as shown in Figure 9. The comparison of the momentum components of the tip leakage flow and the $Q_{g}$ in the GW with those in the SW revealed qualitatively similar tendencies to those in the small tip clearance, as shown in Figure 10 and Figure 11. Moreover, in the GW with the large tip clearance, the blade loading around the groove location decreased compared to that in the SW and the flow near the blade pressure side flowed into the groove, as shown in Figure 7 and Figure 12b. Therefore, much like in the small tip clearance case, the single groove locally increased the negative axialwise and pitchwise momentum components of the tip leakage flow via the reduction of the blade loading and the

Table 2. Mixed-out averaged total pressure loss.

\begin{tabular}{cccc}
\hline Tip clearance & SW $\left(\times 10^{-4}\right)$ & GW $\left(\times 10^{-4}\right)$ & $\mathbf{1 0 0} \times(\mathrm{GW}-\mathrm{SW}) / \mathrm{SW}$ in \% \\
\hline Small & 172.999 & 172.995 & -0.002 \\
Large & 173.398 & 173.380 & -0.011 \\
\hline
\end{tabular}

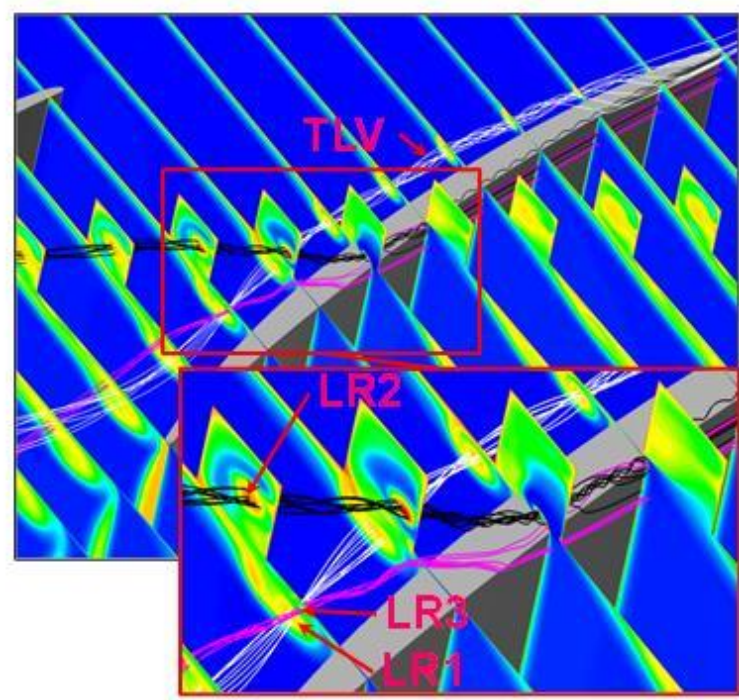

(b) GW (sarge tip clearance)

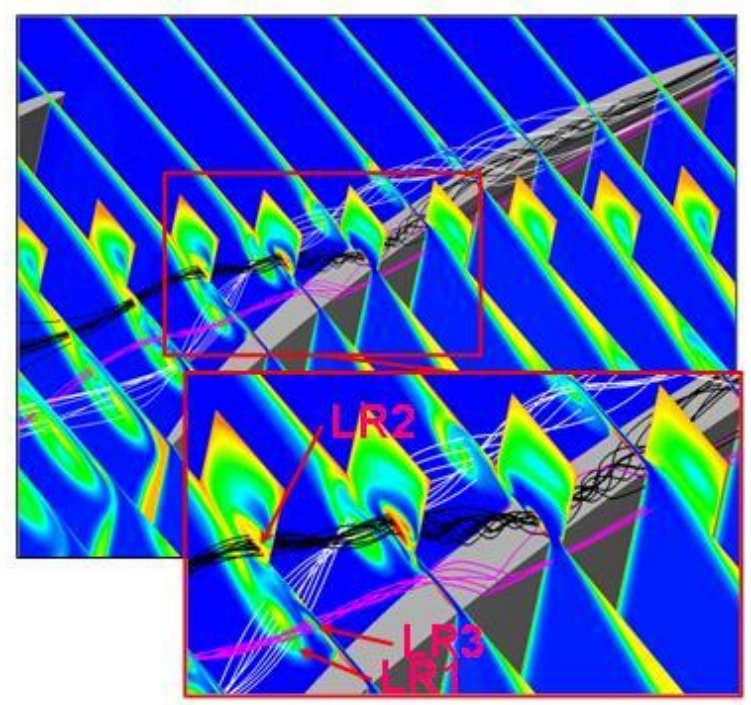

(d) GW (large tip clearance)

flowing of the flow near the blade pressure side into the groove. Consequently, the groove reduced the distance between the TLV core and the blade suction surface.

In terms of the loss generation in the SW, as Figure 13a and Figure $13 \mathrm{c}$ show, the high loss region also distributed around the trajectory of the TLV core in the large tip clearance case. Meanwhile, the $C_{p t 2, m}$ in this case was higher than that in the small tip clearance case, as shown in Table 2 . This was believed to be due to the fact that the loss generation caused by the TLV increased according to the increase in tip clearance. A comparison of the $\mathrm{GW}$ and the $\mathrm{SW}$ in the large tip clearance case revealed that the single groove decreased the loss generation due to the TLV downstream the groove but generated the LR2 and the LR3 in the same manner as in the small tip clearance case, as shown in Figure 13c and Figure 13d.

As a consequence, the $C_{p t 2, m}$ in the GW exhibited a similar value to that in the SW in the large tip clearance case, as shown in Table 2. Therefore, the influence of the single groove on the loss generation in the large tip clearance case was believed to be almost the same as that in the small tip clearance case. 


\section{CONCLUSIONS}

In this study, the influence of the single groove on the flow behaviour and the loss generation in the linear compressor cascade was investigated in terms of both small and large tip clearance cases. The conclusions derived from the study can be summarised as follows:

1) In the cascade with the smooth tip side endwall, the tip leakage vortex was generally generated from the blade leading edge in both the small and the large tip clearance cases. This vortex generated the loss, and this was increased according to the increase in tip clearance size.

2) The single groove installed at the mid-chord locally weakened the tip leakage flow via the reduction of the blade loading and the flowing of the flow near the blade pressure side into the groove, consequently reducing the distance between the tip leakage vortex and the blade suction surface. Moreover, the groove had the effect of decreasing the loss due to the tip leakage vortex generated from the blade leading edge. However, the loss generation in the entire cascade passage was almost the same as that in the cascade without the groove due to the additional loss generation resulting from the presence of the groove. These phenomena were widely observed in both the small and the large tip clearance cases.

\section{REFERENCES}

[1] M. Inoue, M. Kuroumaru, Structure of tip clearance flow in an isolated axial compressor rotor, ASME J. Turbomach 111(3) (1989) pp. 250-256. DOI: $10.1115 / 1.3262263$

[2] J. A. Storer, N. A. Cumpsty, Tip leakage flow in axial compressors, ASME J. Turbomach. 113(2) (1991) pp. 252-259. DOI: $10.1115 / 1.2929095$

[3] S. Kang, C. Hirsch, Experimental study on the three-dimensional flow within a compressor cascade with tip clearance: Part I Velocity and pressure fields, ASME 92-GT-215 (1992) pp. 1-8. DOI: $10.1115 / 92-G T-215$

[4] S. Kang, C. Hirsch, Experimental study on the three-dimensional flow within a compressor cascade with tip clearance: Part II - The tip leakage vortex, ASME, Vol. 92-GT-432 (1992) pp. 1-7. DOI: $10.1115 / 92-G T-432$

[5] S. Kang, C. Hirsch, Tip leakage flow in linear compressor cascade, ASME J. Turbomach. 116(4) (1994) pp. 657-664.

DOI: $\underline{10.1115 / 1.2929458}$

[6] M. Furukawa, M., Inoue, K. Saiki, K. Yamada, The role of tip leakage vortex breakdown in compressor rotor aerodynamics, ASME J. Turbomach. 121(3) (1999) pp. 469-480.

DOI: $\underline{10.1115 / 1.2841339}$

[7] M. Hewkin-Smith, G. Pullan, S. Grimshaw, E. Greitzer, Z. Spakovszky, The role of tip leakage flow in spike-type rotating stall inception, ASME J. Turbomach., 141(6) (2019) p. 061010. DOI: $\underline{10.1115 / 1.4042250}$

[8] H. D. Vo, C. S. Tan, E. M. Greitzer, Criteria for spike initiated rotating stall, ASME J. Turbomach. 130(1) (2008) p. 011023. DOI: $\underline{10.1115 / 1.2750674}$

[9] M. Rolfes, M. Lange, K. Vogeler, R. Mailach, Experimental and numerical investigation of a circumferential groove casing treatment in a low-speed axial research compressor at different tip clearances, ASME J. Turbomach., 139(12) (2017) p. 121009. DOI: $\underline{10.1115 / 1.4037822}$

[10] M. Rolfes, M. Lange, R. Mailach, Investigation of performance and rotor tip flow field in a low speed research compressor with circumferential groove casing treatment at varying tip clearance, International Journal of Rotating Machinery 2017 (2017). Article ID 4631751 .

DOI: $\underline{10.1155 / 2017 / 4631751}$
[11] D. Juan, L. Jichao, G. Lipeng, L. Feng, C. Jingyi, The impact of casing grooves location on stall margin and tip clearance flow in a low-speed axial compressor, ASME J. Turbomach. 138(12) (2016) p. 121007. DOI: $10.1115 / 1.4033472$

[12] T. O. Houghton, I. J. Day, Enhancing the stability of subsonic compressors using casing grooves, ASME J. Turbomach. 133(2) (2011) p. 021007.

DOI: $\underline{10.1115 / 1.4000569}$

[13] T. Houghton, I. Day, Stability enhancement by casing grooves: the importance of stall inception mechanism and solidity, ASME J. Turbomach. 134(2) (2012) p. 021003.

DOI: $\underline{10.1115 / 1.4002986}$

[14] A. Shabbir, J. J. Adamczyk, Flow mechanism for stall margin improvement due to circumferential casing grooves on axial compressors, ASME J. Turbomach. 127(4) (2005) pp. 708-717. DOI: $\underline{10.1115 / 1.2008970}$

[15] M. H. Ross, J. D. Cameron, S. C. Morris, H. X. Chen, K. Shi, Axial compressor stall, circumferential groove casing treatment, and the tip-clearance momentum flux, Journal of Propulsion and Power 34(1) (2018) pp. 146-152.

DOI: $\underline{10.2514 / 1 . B 36181}$

[16] J. C. Li, F. Lin, S. C. Wang, J. Du, C. Q. Nie, J. Y. Chen, Extensive experimental study of circumferential single groove in an axial flow compressor, Proceedings of ASME Turbo Expo, 2014, GT2014-26859. DOI: $10.1115 /$ GT2014-26859

[17] Y. Wu, W. Chu, H. Zhang, Q. Li, Parametric investigation of circumferential grooves on compressor rotor performance, ASME J. Fluids Eng. 23(12) (2010) pp. 1-10. DOI: $10.1115 / 1.4003000$

[18] M. Lange, M. Rolfes, R. Mailach, H. Schrapp, Periodic unsteady tip clearance vortex development in a low-speed axial research compressor at different tip clearances, ASME J. Turbomach. 140(3) (2017) p. 031005. DOI: $10.1115 / 1.4038319$

[19] C. Hah, Effects of double-leakage tip clearance flow on the performance of a compressor stage with a large rotor tip gap, ASME J. Turbomach. 139(6) (2016) p. 061006. DOI: $10.1115 / 1.4035521$

[20] S. Sakulsaew, C. S. Tan, E. Donahoo, C. Cornelius, M. Montgomery, Compressor efficiency variation with rotor tip gap variation from vanishing to large clearance, ASME J. Turbomach. 135(3) (2013) p. 031030. DOI: $10.1115 / 1.4007547$

[21] B. H. Beheshti, J. A. Teixeira, P. C. Ivey, K. Ghorbanian, B. Farhanieh, Parametric study of tip clearance-casing treatment on performance and stability of a transonic axial compressor, ASME J. Turbomach. 126(4) (2004) pp. 527-535.

DOI: $\underline{10.1115 / 1.1791643}$

[22] C. Muthanna, The effects of free stream turbulence on the flow field through a compressor cascade, Ph.D. Dissertation, Virginia Polytechnic Inst. and State Univ, 2002.

[23] F. R. Menter, Two-equation eddy-viscosity turbulence models for engineering applications, AIAA-Journal 32(8) (1994) pp.269-289. DOI: $\underline{10.2514 / 3.12149}$

[24] M. Kaneko, Influence of incidence angle on behavior of tip leakage flow in linear compressor cascade, Turbomachinery 47(10) (2019) pp. 27-34 (In Japanese). DOI: $10.11458 /$ tsj. 47.10603

[25] H. Chen, X. Huang, K. Shi, S. Fu, M. Ross, M., Bennington, J. D. Cameron, S. C. Morris, S. McNulty, A. Wadia, A computational fluid dynamics study of circumferential groove casing treatment in a transonic axial compressor, ASME J. Turbomach. 136(3) (2013) p. 031003.

DOI: $\underline{10.1115 / 1.4024651}$

[26] A. Prassad, Calculation of the mixed-out state in turbomachine flows, ASME J. Turbomach. 127(3) (2005) pp. 564-572. DOI: $10.1115 / 1.1928289$ 